\title{
Using geographical information system for spatial evaluation of canine extruded disc herniation
}

\author{
Constantin Daraban ${ }^{1}$, Carla Murino², Giuseppe Marzatico $^{3}$, Giuseppina Mennonna ${ }^{2}$, \\ Gerardo Fatone $^{3}$, Luigi Auletta ${ }^{4}$, Fabiana Micieli ${ }^{3}$, Vasile Vulpe ${ }^{1}$, Leonardo Meomartino ${ }^{2}$ \\ ${ }^{1}$ Clinics Department, Faculty of Veterinary Medicine, "Ion Ionescu de la Brad" University of Agricultural \\ Sciences and Veterinary Medicine of Iasi, Iasi, Romania; Interdepartmental Veterinary Radiology Centre, \\ University of Naples Federico II, Naples, Italy; ${ }^{3}$ Department of Veterinary Medicine and Animal Production, \\ University of Naples Federico II, Naples, Italy; ${ }^{4}$ Istituto di Ricovero e Cura a Carattere Scientifico, Società di \\ Diagnostica Nucleare, Naples, Italy
}

\begin{abstract}
Disc herniation is one of the most common pathologies of the vertebral column in dogs. The aim of this study was to develop a geographical information system (GIS)-based vertebral canal (VC) map useful for spatial evaluation of extruded disc herniation $(\mathrm{EDH})$ in dogs. ArcGIS ${ }^{\circledR}$ was used to create two-dimensional and three-dimensional maps, in which the VC surface is divided into polygons by lines representing latitude and longitude. Actual locations and directions of the herniated disc material were assessed by a series of 142 computer tomographies of dogs collected between 2005 and 2013. Most EDHs were located on the cervical and transitional regions (thoraco-lumbar and lumbo-sacral) and shown at the level of the ventro-cranial and ventro-central polygons created. Choropleth maps, highlighting the distribution and the location/direction patterns of the EDHs throughout the VC, were produced based on the frequency of the ailment. GIS proved to be a valuable tool in analysing EDH in dogs. Further studies are required for biomechanical analysis of EDH patterns.
\end{abstract}

Keywords: dog, disc herniation, computer tomography, geographical information system.

\section{Introduction}

Geographical information systems (GIS) represent a most useful approach to modelling spatial relationships and real processes (Schweikart et al., 2012), capturing and displaying all forms of geographically referenced information. In order to manage and analyse the information collected, a computer with special, dedicated software is needed to allow the visualisation, understanding and data interpretation in the form of structures such as maps, globes and reports, which reveal relationships, patterns and trends of the given data. GIS technology contributes to a quick grasp of various phenomena by comparing their locations expressed as latitudes and longitudes. The real advantage of GIS is, however, that it permits many different data formats (e.g. digital data, maps and tables) to be displayed (e.g. in the form of overlays) that can be added one on top of another on a base map. Many dif-

Corresponding author: Leonardo Meomartino

Interdepartmental Veterinary Radiology Centre

University of Naples Federico II

Via F. Delpino 1, 80137 Naples, Italy

Tel. +39 081 253-6042; Fax +39-081 253-6021

E-mail: leonardo.meomartino@unina.it ferent types of information, no matter of their source or original format, can be demonstrated this way showing various pieces of important information (e.g. number, frequency and distribution of a phenomenon) simultaneously.

One of the first environmental epidemiological studies for companion animals was published in 1970 (Reif and Cohen, 1970). Indeed, GIS was first applied for epidemiological studies both in the human (Clarke et al., 1996) and the veterinary (Rinaldi et al., 2006) fields. However, it has more recently been shown to be useful also in approaching other types of analysis (Durr and Gatrell, 2004). For example, in human medicine, GIS has been demonstrated to be efficient in creating an anatomic dental chart (Bartling and Schleyer, 2003), an anatomical and radiological digital brain map (Juanes et al., 2012) as well as approaching the spatial analysis of the rectum (Ganai et al., 2006) and rectal lesions (Garb et al., 2007).

A tentative area for GIS application in the anatomical, veterinary field is presented by the dog vertebral column, which consists of vertebrae linked together by intervertebral discs. Dogs have approximately 50 vertebrae divided into five different regions: cervical, thoracic, lumbar, sacral and coccygeal (or caudal). To distinguish each vertebra in the cranio-caudal direction, there is a generally used abbreviation, in which a letter 
indicates the vertebral region followed by a number that specifies the vertebra in question within this region. The vertebral formula for the dog is C1-7 T113 L1-7 S1-3 Cd1-20 (the latter figure can vary between 6 and 23) (Evans and De Lahunta, 2012). A typical vertebra is formed by a body, a vertebral arch, which consists of right and left pedicles sustaining a lamina plus a number of processes that serves the purpose of muscle attachment or has a particular form to fit adjacent vertebrae. Together with the body, the arch forms a short tube named the vertebral foramen and together these foramina form the vertebral canal (VC) that encloses the spinal cord. Thus, the main role of the vertebrae is to protect the spinal cord and the roots of the spinal nerves, contributing to supporting the head and in providing attachment for the muscles governing body movements (Evans and De Lahunta, 2012). To unite the bodies of adjacent vertebrae, intervertebral discs are interposed in every intervertebral space except in the C1-C2 intervertebral space.

At the VC level, various types of lesion may damage the spinal cord: congenital anomalies, trauma, inflammation, neoplasms and degeneration (da Costa and Moore, 2010). However, in dogs with spinal cord injuries, intervertebral disc herniation is the most commonly encountered pathology from of all lesions (Brisson, 2010; Jeffery et al., 2013). Hansen (1952) described two distinct forms of herniation, each typically occurring in different types of dog: (i) extrusion of the degenerate nucleus (type I); and (ii) protrusion of the degenerating annulus into the VC (type II). Type I disc herniation is described usually in chondrodystrophic dogs belonging to breeds, such as Pekingese, Dachshund and Beagle, among others (Goggin et al., 1970; Priester, 1976; Brisson et al., 2004), while type II disc herniation is particularly encountered in largebreed dogs, especially the German shepherd (Downes et al., 2009). However, there are reports indicating the presence of type I disc herniation in large-breed, nonchondrodystrophic breeds (Cudia and Duval, 1997; Macias et al., 2002) as well as the occurrence of type II disc herniation in small, chondrodysrophic breed dogs (Besalti et al., 2006; Levine et al., 2006). Extruded disc herniation (EDH) generally shows the expression of most dramatic neurologic deficits (Macias et al., 2002). Since the herniated material could result from any intervertebral disc spaces (except C1-C2 and sacrum), the vertebral canal might be considered a "destination", into which disc material from several sites arrive. Although many authors have described the localisation of the EDH considering the prevalence of the events in a given space (Jeffery et al., 2013), disc material protruding into the VC has so far not been considered.

We hypothesise that GIS could provide a reliable tool suitable to better describe the site of the EDH and the type of the "movement" made by the extruded disc material pressed into the VC with respect to the intervertebral disc space and the adjacent vertebral bodies. However, available GIS dataset for spatial analysis of VC surface in dogs are lacking. Therefore, the aim of this study was to develop a GIS-based map of the canine VC helpful to better characterise and understand the displacement mode of the EDH inside the $\mathrm{VC}$ in dogs.

\section{Materials and methods}

Location and situation of the EDH was assessed by computerised tomography (CT) in 142 dogs presented to the Interdepartmental Veterinary Radiology Centre between 2005 and 2013. All CT studies were performed using a helical (single layer) CT scanner (General Electric Prospeed ${ }^{\circledR}$, Fairfield, USA) and all data referring to breed, sex, age and weight of the subjects were recorded. Every EDH was identified and recorded according to position and location including single (protrusion of only one intervertebral disc) or multiple patterns (protrusion of more than one intervertebral disc in the same dog). The diagnosis of Hansen type I disc herniation was made on the basis of characteristics described above and in more detail by Olby et al. (2000) and Lim et al. (2010).

In order to convert the canine VC into a GIS model, the $\mathrm{VC}$ was considered as a long, segmented cylinder. GIS-dedicated software (ArcGIS version 10.2.1, ESRI; Redlands, USA) was used to create two-dimensional (2-D) and three-dimensional (3-D) maps, in which VC surface was divided in polygons by lines representing latitude and longitude. The starting point was to draw a scheme of the proposed VC anatomy (Fig. 1) to achieve a model easily adaptable for the ArcGIS software. A cylindrical model of the VC with 78 latitudinal and eight longitudinal lines producing 624 polygons was created. In order to simplify the GIS model of the VC, an intervertebral space ratio of $2: 1$ was chosen (anatomically, the ratio is approximately 7:1) (Evans and De Lahunta, 2012). Considering the latitudinal reference, each vertebra was formed by two polygon series, i.e. a cranial one $(\mathrm{Cr})$ and a caudal one (Ca), while the intervertebral spaces were represented by a single central polygon series (Ce). The EDH position would then be represented by one of the aforementioned polygons, i.e. $\mathrm{Cr}$, $\mathrm{Ce}$ or $\mathrm{Ca}$. 

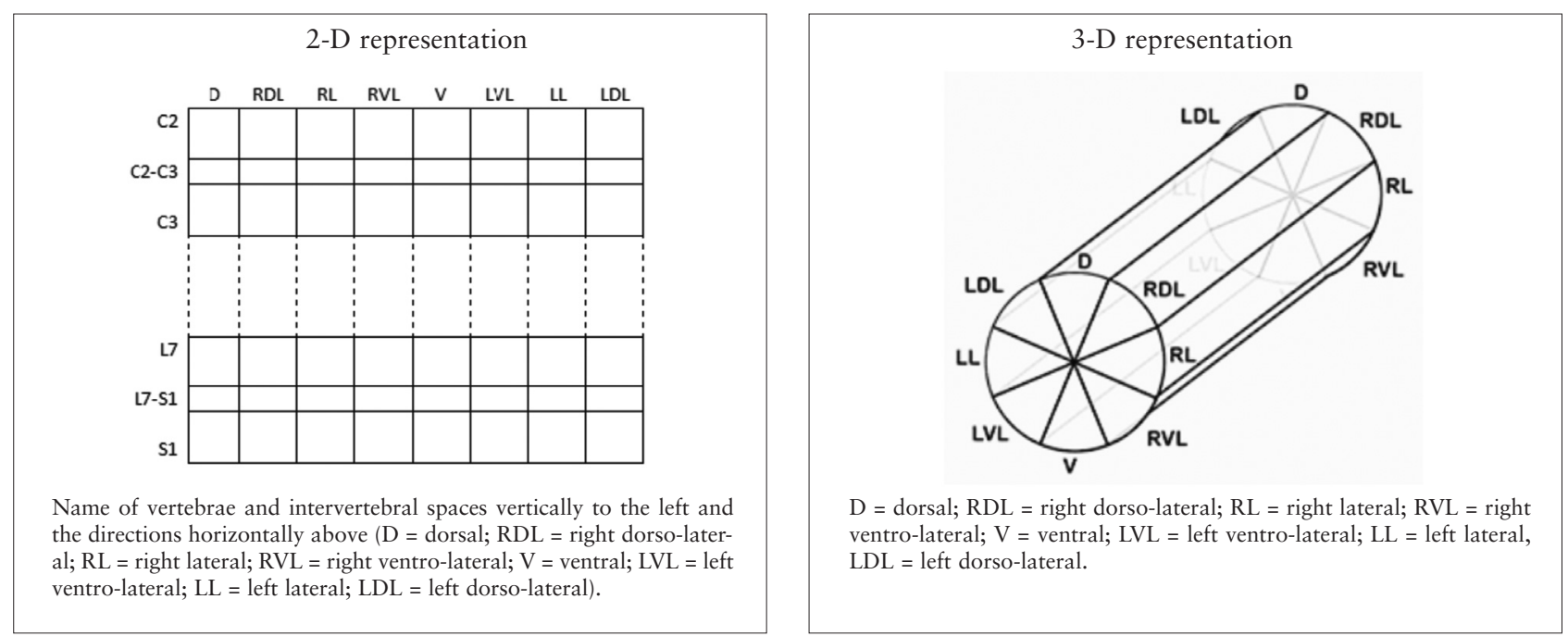

Fig. 1. Schematic 2-D and 3-D representation of the vertebral canal in dog.

The vertebral location code was given according to the anatomic segment (either cervical, thoracic, lumbar or sacral), so each vertebra could be located by its specific code number (e.g. T9 represents the ninth thoracic vertebra). The intervertebral space was named by the adjacent vertebrae which formed it (e.g. T9-T10 represent the intervertebral space between the vertebrae T9 and T10). Due to the lack of an intervertebral disc between $\mathrm{C} 1$ and $\mathrm{C} 2$ and to the fusion of the sacral vertebrae (S1-S3), the intervertebral spaces between these vertebrae were not included. Each longitudinal polygon series were divided in eight polygons, representing EDH locations as either ventral $(\mathrm{V})$, left ventro-lateral (LVL), right ventro-lateral (RVL), left lateral (LL), right lateral (RL), left dorso-lateral (LDL), right dorso-lateral (RDL) or dorsal (D) (Fig. 1). The location and the direction of the extrusion of the EDH determine the position and situation of the EDH throughout the VC. Therefore, the extruded disc material could spill over into one of the mentioned polygons (e.g. Cr-V meaning cranio-ventral protrusion).

To create the cylindrical 3-D representation of the VC (Fig. 2), the theoretical circumference (360 degrees) of the $\mathrm{VC}$ was divided by the number of polygonal elements $(n=8)$ needed to represent each possible extrusion. Each polygon was thus defined as 45 degrees wide. Subsequently, for each polygon a set of four points was defined: the vertices relatives to the crossings between the latitude and longitude lines of the border of each polygon and then, the three coordinates needed to locate the position in a 3-D space were calculated for each point as follows:

(i) $\mathrm{x}$ representing the longitude or the position of the point inside the circumference of the VC; (ii) y representing the latitude or the position of the point relative to the height of the VC;

(iii) $\mathrm{z}$ representing the distance between the centre of the hypothetical VC and the circumference; thus, $\mathrm{z}$ is the radius of the circumference representing the section of the VC.

To represent the height of the VC a custom "depth" value was defined. The depth parameters represent the height of the VC. The mathematical formulas used to generate the 3-D model points were:

(i) $\mathrm{x}=\cos ($ element $\mathrm{x}$ segment $\mathrm{x} 45)$;

(ii) $\mathrm{y}=\sin$ (polygonal_element_border_point $\mathrm{x} 45$ ); and

(iii) $\mathrm{z}=$ (longitudinal_polygon_series_number) $\mathrm{x}$ depth.

The 2-D model was created starting from the 3-D model not taking into account the angular length of each element. The depth was set to zero.

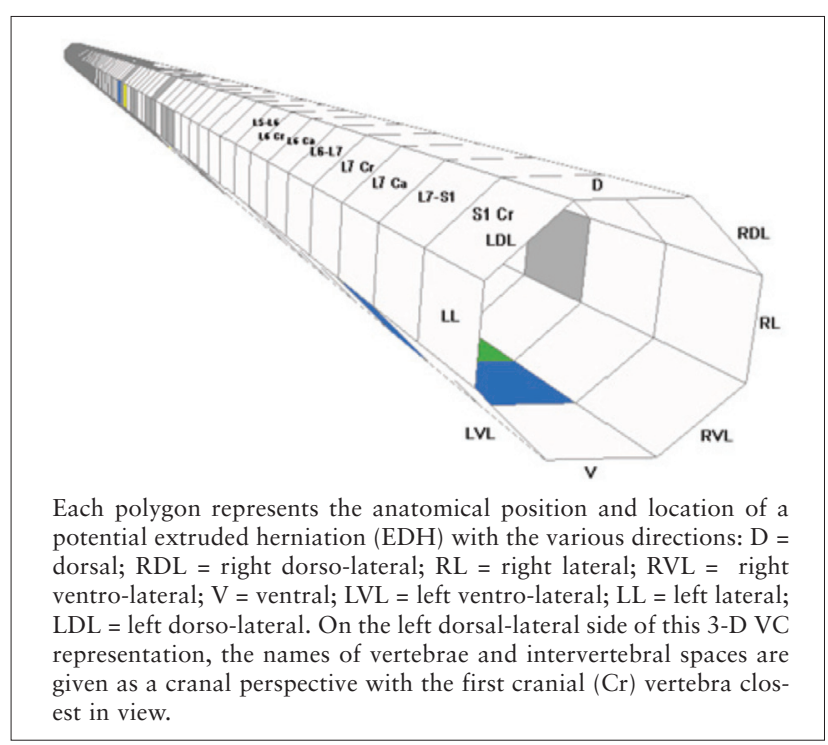

Fig. 2. Schematic 3-D representation of the VC. 


\section{Statistical analysis}

All data were imported in an electronic spreadsheet (Microsoft Excel ${ }^{\odot}$ ) prior to importing them in a programme for statistical analysis (JMP ${ }^{\circledR}$, SAS Institute, Inc., Cary, USA). All data were explored by using contingency table and $\chi^{2}$ test. The statistical significance level was set at $\mathrm{P}<0.05$.

\section{Results}

The results of the 2-D and 3-D mapping process for anatomic regions and lesion distribution are shown in Fig. 3 (choropleth maps). Each region of the VC is formed by polygons and named according to the anatomic segment: cervical, thoracic, lumbar or sacral. On the transverse view, the polygons of the cylinder are named according to anatomical orientation of the VC (left/right, ventral/dorsal), where EDH could be though to extrude. On the sagittal view, polygon labels indicated the anatomical name of each vertebral segment (cranial/caudal) or intervertebral space (central). The 2-D and 3-D choropleth maps were realised based on frequency of EDH protrusions showing the distribution of EDH throughout the VC. Most EDHs were located on cervical and transitional regions (thoraco- lumbar and lumbo-sacral) at the level of the ventrocranial and ventro-central polygons (Fig. 4). The 3-D map approach allows a more realistic exploration of the $\mathrm{VC}$ and the lesion pattern determined by EDH extrusion.

Mixed-breed dogs were the most common in the study, counting 47 subjects. Other breeds included Dachshund (18), German shepherd (11), Dalmatian (9), Pekingese (8), Beagle (6), Yorkshire terrier (5), Maltese (4), Miniature pinscher (4), Jack Russell terrier (3), Rottweiler (3), Shih tzu (3), Cocker spaniel (2), French bulldog (2), Golden retriever (2), Labrador retriever (2), Poodle (2) and one each of other breeds (Basset hound, Bichon bolognese, Boxer, Cane corso, English bulldog, Great dane, Lagotto romagnolo, Pit bull, Pug, Segugio italiano and Terranova). Ninety-one were males ( 2 castrated) and 51 females (14 neutered). The mean age was 7 years (range 2-15 years). The mean weight was $16.3 \mathrm{~kg}$ (range $2.7-65 \mathrm{~kg}$ ).

A total of 177 EDHs were diagnosed, 25 dogs $(17.6 \%)$ having more than one intervertebral space affected (the multiple pattern). The mean $\mathrm{EDH} / \mathrm{dog}$ was 1.3 (range, 1 to $5 \mathrm{EDH}(\mathrm{s}) / \mathrm{dog}$ ). The most commonly affected intervertebral disc space was T12-T13 $(18.1 \%)$, followed by L1-L2 $(10.2 \%)$ and T13-L1

2-D representation
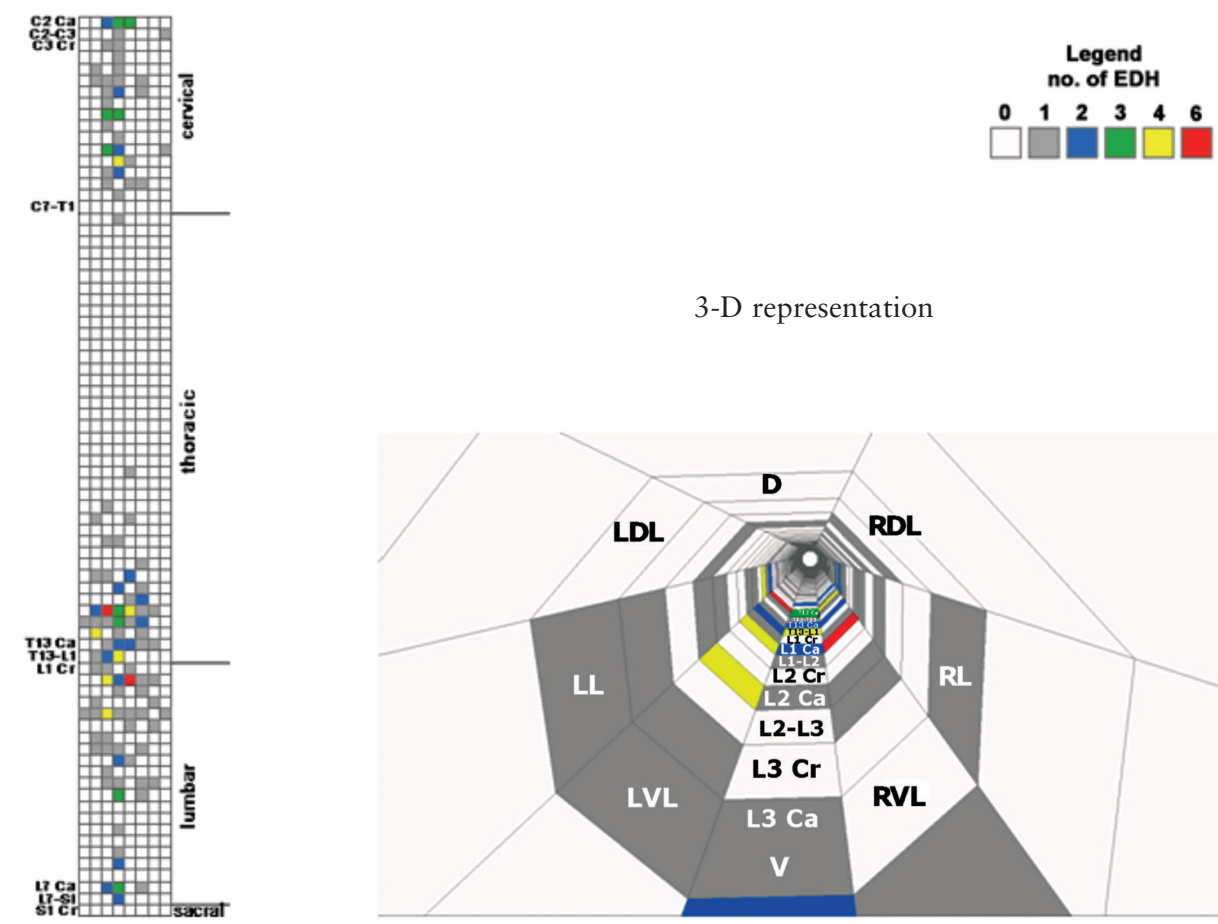

3-D representation

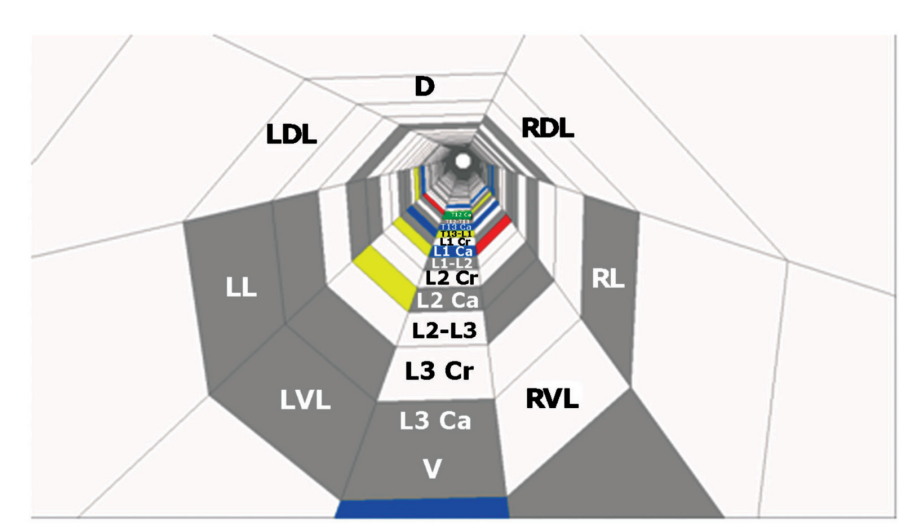

Fig. 3. Choropleth maps showing the distribution of extruded disc herniations (EDH) throughout the vertebral canal. 
(9.6\%). Depending on the position of the EDH, 91 disc extrusions were located cranially, 46 centrally and 40 caudally (Table 1 ).

Depending on location, $60(33.9 \%)$ of the disc herniations were located at points along the ventral part (V) of the VC with a lower frequency of all other positions (Table 2), but there was no statistically significant difference between the intervertebral disc space and the location of the EDHs $(\mathrm{P}=0.96)$. A non-significant difference was, however, recorded between the right and the left side $(\mathrm{P}=0.19)$ (sideways of the ventro-dorsal line), $52 \mathrm{EDHs}$ were found on the right side and 62 on the left. There were no differences on the lateralisation when considering the specific intervertebral spaces $(P=0.23)$. A cranial position of the extruded disc material was more frequently observed with respect to the L1-L2 $(12$, expected value (e.v. $)=8)$ and L2-L3 $(9$, e.v. $=6)$ intervertebral disc spaces, while a caudal position of the extruded disc material was more frequently observed at C3-C4 (4, e.v. = 1), C4-C5 (6, e.v. $=2)$, C5-C6 $(6$, e.v. $=2)$ disc spaces and significant- ly less frequently observed at the Ll-L2 (1, e.v. 4) $(\mathrm{P}=$ 0.02) disc space.

The single pattern was significantly more frequently seen at T12-T13 $(21.1 \%)$, L1-L2 $(9.2 \%)$ and C2-C3 $(8.5 \%)$ disc spaces, whereas the multiple pattern was significantly more frequent at the T13-L1 $(19.4 \%)$, L1-L2 (13.9\%) and L3-L4 (13.9\%) (P = 0.007) levels (Table 3). Breed and sex showed no significant effect on intervertebral space involved, location or position.

\section{Discussion}

To the best of our knowledge, this is the first time in which a GIS-based map of the vertebral canal in dogs was proposed. The application of GIS for anatomical evaluation of different lesions is poorly represented in the medical literature, particularly in the veterinary medicine. There are no previous studies demonstrating the utility of GIS in analysing the anatomy of VC and distribution pattern of extruded disc material in dogs. Starting from the GIS-based map of the human rectum
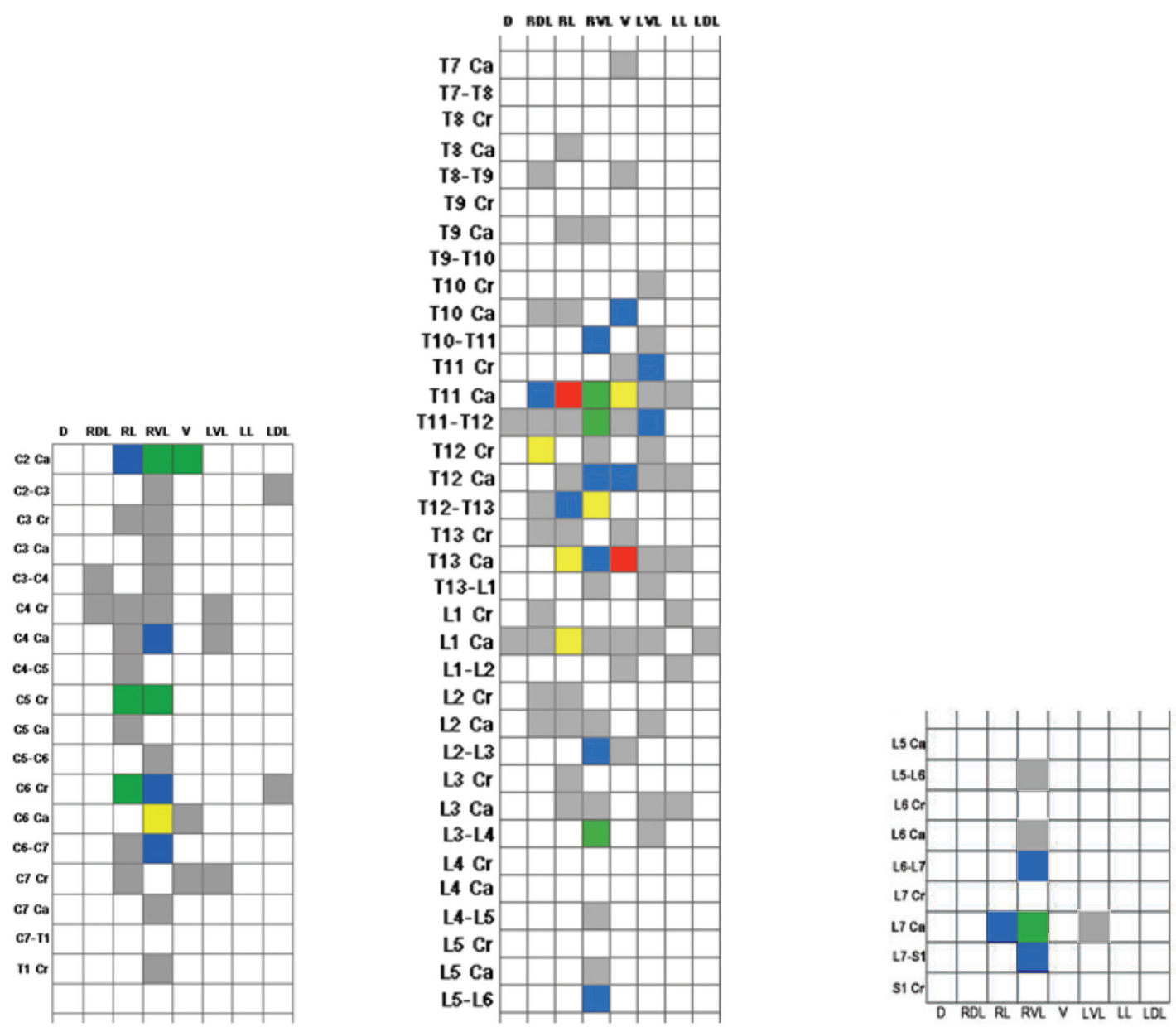

Fig. 4. Close up of the choropleth maps of the main regions affected by EDHs. The cervical region (left); the thoracolumbar junction (middle); the lumbosacral junction (right). 
Table 1. Distribution and position of EDHs by intervertebral space.

\begin{tabular}{|c|c|c|c|c|}
\hline \multirow{2}{*}{$\begin{array}{l}\text { Intervertebral } \\
\text { space }\end{array}$} & \multirow{2}{*}{$\begin{array}{c}\text { No. of } \\
\text { herniations }\end{array}$} & \multicolumn{3}{|c|}{ Position of EDH } \\
\hline & & Cranial & Central & Caudal \\
\hline $\mathrm{C} 2-\mathrm{C} 3$ & 12 & 8 & 2 & 2 \\
\hline $\mathrm{C} 3-\mathrm{C} 4$ & 7 & 1 & 2 & 4 \\
\hline $\mathrm{C} 4-\mathrm{C} 5$ & 11 & 4 & 1 & 6 \\
\hline C5-C6 & 8 & 1 & 1 & 6 \\
\hline C6-C7 & 11 & 5 & 3 & 3 \\
\hline C7-T1 & 2 & 1 & 0 & 1 \\
\hline $\mathrm{T} 1-\mathrm{T} 2$ & 0 & 0 & 0 & 0 \\
\hline $\mathrm{T} 2-\mathrm{T} 3$ & 0 & 0 & 0 & 0 \\
\hline T3-T4 & 0 & 0 & 0 & 0 \\
\hline T4-T5 & 0 & 0 & 0 & 0 \\
\hline T5-T6 & 0 & 0 & 0 & 0 \\
\hline T6-T7 & 0 & 0 & 0 & 0 \\
\hline T7-T8 & 0 & 0 & 0 & 0 \\
\hline T8-T9 & 1 & 1 & 0 & 0 \\
\hline T9-Т10 & 3 & 1 & 2 & 0 \\
\hline T10-T11 & 3 & 2 & 0 & 1 \\
\hline T11-T12 & 10 & 4 & 3 & 3 \\
\hline T12-T13 & 32 & 17 & 9 & 6 \\
\hline T13-L1 & 17 & 7 & 7 & 3 \\
\hline L1-L2 & 18 & 14 & 2 & 2 \\
\hline L2-L3 & 14 & 10 & 2 & 2 \\
\hline L3-L4 & 8 & 4 & 3 & 1 \\
\hline L4-L5 & 8 & 4 & 4 & 0 \\
\hline L5-L6 & 1 & 0 & 1 & 0 \\
\hline L6-L7 & 3 & 1 & 2 & 0 \\
\hline L7-S1 & 8 & 6 & 2 & 0 \\
\hline TOTAL & 177 & 91 & 46 & 40 \\
\hline
\end{tabular}

Table 2. Distribution the disc herniations by direction.

\begin{tabular}{lcc}
\hline Location & Number of lesions & Distribution (\%) \\
\hline Ventral (V) & 60 & 33,9 \\
Right lateral (RL) & 19 & 10.7 \\
Left lateral (LL) & 17 & 9.6 \\
Right ventro-lateral (RVL) & 27 & 15.3 \\
Left ventro-lateral (LVL) & 43 & 24.3 \\
Dorsal (D) & 3 & 1.7 \\
Right dorso-lateral (RDL) & 6 & 3.4 \\
Left dorso-lateral (LDL) & 2 & 1.1 \\
\hline
\end{tabular}

and its importance in characterising the rectal lesions (Ganai et al., 2006; Garb et al., 2007), we hypothesised that it would be useful to characterise the VC and lesion pattern of EDH in dogs based on GIS. The two major points of the present study are: (i) anatomical description of VC in dogs based on GIS; and (ii) GIS-based representation of the pattern of the EDH extrusion.

CT represents a reliable, non-invasive diagnostic imaging modality useful for localisation and characterisation of EDH in dogs (Israel et al., 2009; Newcomb et al., 2012). In our study, the CT was used to differentiate the Hansen type I disc herniation and to define the actual location of the extruded disc material inside the VC. We feel that a useful, although necessarily simplified model of the VC based on GIS data was made. The model has a 3-D cylindrical shape that can be view in a 2-D mode too on which frequency of EDHs is represented by a cloropleth map. Spatial relationships are better showed by a 2-D map due to the available overview of the entire structure. Thus, the advantage of 2-D mapping is the possibility of viewing and analysing, the entire spatial plane as a whole, which gives the possibility of interpreting the phenomenon on a large scale, in our case represented by the frequency and the distribution of EDH throughout the VC.

The 3-D choropleth map gives the possibility of visualising in a more realistic way, the distribution of $\mathrm{EDH}$ along the VC. The advantage of this spatial representation is that it enables the possibility of interpreting all lesion patterns in a comparable, very similar way. However, the 3-D map is unable to show all the data simultaneously because of the length of the $\mathrm{VC}$, so the different parts of the VC must be visualised one by one.

The frequency of EDH depends on the anatomical segment of the VC, thus higher frequency is noticed at cervical region and thoraco-lumbar and lumbo-sacral junctions. The most affected intervertebral disc spaces were: T12-T13, L1-L2, T13-L1, L2-L3, C2-C3, C4C5 and C6-C7, these data being in agreement with previous reports (Brisson, 2010; Jeffery et al., 2013). The susceptibility of EDH at the level of thoraco-lumbar junction is explained by the large mobility on this region due to the junction between the relatively rigid lumbar and thoracic regions (Hansen, 1952; Bray and Burbidge, 1998). The explanation of EDH occurring in the lumbo-sacral region could be increased or altered mechanical load on the intervertebral disc there (Benninger et al., 2004) or due to vertebral deformities, which are very common at the level of this region (Fluckiger et al., 2006). The higher incidence of 
Table 3. Distribution pattern of extruded disc herniations by intervertebral space.

\begin{tabular}{|c|c|c|c|c|c|c|c|c|c|c|c|c|c|c|c|c|c|c|c|c|c|c|c|c|c|c|c|}
\hline $\begin{array}{l}\text { Interverte } \\
\text { disc space }\end{array}$ & & 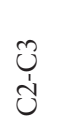 & $\underset{J}{\circlearrowright}$ & $\begin{array}{l}\mathfrak{u}_{1}^{\prime} \\
\dot{J}\end{array}$ & 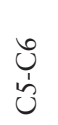 & $\hat{U}$ & $\underset{\mathcal{U}}{\mathcal{H}}$ & $\frac{N}{\stackrel{1}{F}}$ & $\stackrel{n}{\stackrel{n}{N}}$ & $\begin{array}{l}+ \\
\stackrel{\bullet}{\ominus} \\
\stackrel{n}{H}\end{array}$ & $\begin{array}{l}n \\
\stackrel{1}{+} \\
F\end{array}$ & $\begin{array}{l}6 \\
\stackrel{1}{n} \\
\mapsto\end{array}$ & $\stackrel{\hat{b}}{b}$ & $\stackrel{\substack{1 \\
H}}{\stackrel{1}{H}}$ & $\begin{array}{l}a \\
\cdots \\
b\end{array}$ & $\begin{array}{l}\stackrel{0}{=} \\
\vec{F}^{\prime} \\
\stackrel{\sigma}{\models}\end{array}$ & $\begin{array}{l}\text { 二 } \\
F_{1} \\
\text { ○ } \\
\text { F }\end{array}$ & $\underset{\stackrel{\sim}{F}}{\stackrel{\sim}{二}}$ & $\begin{array}{l}\stackrel{n}{\rightleftharpoons} \\
\stackrel{1}{\sim} \\
F\end{array}$ & $\begin{array}{l}\overrightarrow{1} \\
\stackrel{\sigma}{F}\end{array}$ & $\underset{ت}{ت}$ & $\begin{array}{l}3 \\
\\
\end{array}$ & 音 & $\stackrel{n}{3}$ & 光 & . & 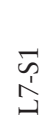 \\
\hline Total & No. & 12 & 7 & 11 & 8 & 11 & 2 & 0 & 0 & 0 & 0 & 0 & 0 & 0 & 1 & 3 & 3 & 10 & 32 & 17 & 18 & 14 & 8 & 8 & 1 & 3 & 8 \\
\hline $\mathrm{EDH}$ & $\%$ & 6.8 & 3.9 & 6.2 & 4.5 & 6.2 & 1.1 & 0 & 0 & 0 & 0 & 0 & 0 & 0 & 0.6 & 1.7 & 1.7 & 5.6 & 18.1 & 9.6 & 10.2 & 7.9 & 4.5 & 4.5 & 0.6 & 1.7 & 4.5 \\
\hline Single & No. & 12 & 7 & 9 & 6 & 8 & 2 & 0 & 0 & 0 & 0 & 0 & 0 & 0 & 0 & 3 & 3 & 10 & 30 & 11 & 13 & 10 & 3 & 5 & 0 & 2 & 8 \\
\hline Pattern & $\%$ & 8.4 & 4.9 & 6.3 & 4.2 & 5.6 & 1.4 & 0 & 0 & 0 & 0 & 0 & 0 & 0 & 0 & 2.1 & 2.1 & 7.0 & 21.1 & 7.7 & 9.1 & 7.0 & 2.1 & 3.5 & 0 & 1.4 & 5.6 \\
\hline Multiple & No. & 0 & 0 & 2 & 2 & 3 & 0 & 0 & 0 & 0 & 0 & 0 & 0 & 0 & 1 & 0 & 0 & 0 & 2 & 7 & 5 & 4 & 5 & 3 & 1 & 1 & 0 \\
\hline Pattern & $\%$ & 0 & 0 & 5.6 & 5.6 & 8.3 & 0 & 0 & 0 & 0 & 0 & 0 & 0 & 0 & 2.8 & 0 & 0 & 0 & 5.6 & 19.4 & 13.9 & 11.1 & 13.9 & 8.3 & 2.8 & 2.8 & 0 \\
\hline
\end{tabular}

EDH at the caudal cervical spine is explained by the relative increase in cord size and the increased mobility of this region at the level of cervical intumescence (Fitch et al., 2000; da Costa, 2010).

Depending on location inside the VC, almost three quarters $(73.5 \%)$ of the total of $\mathrm{EDH}$ were located on the ventral side, while $20.3 \%$ were located on the lateral side and only a small proportion of EDH were located on the dorsal side $(6.2 \%)$. On the lumbar spine, the position of extruded disc material was noticed cranially more frequently, while on the cervical spine the EDH was prone to move caudally. In a previous study (Lim et al., 2010), the ventral location of extruded disc material was higher $(88.2 \%)$, while dorsal location recorded a lower incidence $(2.4 \%)$, maybe because that study was conducted only on the thoraco-lumbar intervertebral disc herniations. This displacement pattern of EDH is in part an obvious subsequence to the fact that the vertebral canal is not an empty structure and therefore the disc material cannot move freely. However, considering the prevalence of cranial displacement compared with the central or caudal one (91/46/40), we supposed that there is a strong connection between anatomical structure of the $\mathrm{VC}$ and the displacement pattern of $\mathrm{EDH}$, but more studies are needed to confirm this.

Similarly, our results showed a higher left sided herniation in the lateral location, in agreement with the previously mentioned study (Lim et al., 2010). The GIS-based map of the VC easily permitted to visualise the displacement pattern of extruded disc material, but more studies are needed to clarify the underlying biomechanical causes.

\section{Conclusion}

Starting from the anatomical structure of the vertebral canal, it is possible to realise a GIS-based map where it is easy to insert different physiological or pathological data which can lead to a characterisation of a specific pattern. Combining GIS and CT makes it possible to realise a map useful to view and analyse the dislocation pattern of EDH into the VC in dogs. The mapping of the vertebral canal in dogs is a new concept with real advantages for veterinary clinicians in understanding the dynamic of EDH and represents a new interdisciplinary direction which can be more developed in the near future. Representation of these data in the form of a map could facilitate recognition, interpretation and synthesis of frequency and occurrence of various phenomena.

\section{Acknowledgements}

The authors are grateful to USAMV Iasi, for its financial support from the project entimed "Improvement and development of human resources for research and innovation by doctoral school"; contract: POSDRU-CPP107-DMI1/5/S/77222, given for the mobility of Ph.D. student Constantin Daraban.

\section{References}

Bartling WC, Schleyer TK, 2003. An application of geospatial information system (GIS) technology to anatomic dental charting. AMIA Annu Symp Proc, 786.

Benninger MI, Seiler GS, Robinson LE, Ferguson SJ, Bonel HM, Busato AR, Lang J, 2004. Three-dimensional motion pattern of the caudal lumbar and lumbosacral portions of the vertebral column of dogs. Am J Vet Res 65, 544-551.

Besalti O, Pekcan Z, Sirin Y, Erbas G, 2006. Magnetic resonance imaging in dogs with thoracolumbar intervertebral disk disease: 69 cases (1997-2005). J Am Vet Med Assoc 15, 902908.

Bray JP, Burbidge HM, 1998. The canine intervertebral disk: part one: structure and function. J Am Anim Hosp Assoc 34, 55-63.

Brisson BA, 2010. Intervertebral disc disease in dogs. Vet Clin North Am Small Anim Pract 40, 829-858. 
Brisson BA, Moffatt SL, Swayne SL, Parent JM, 2004. Recurrence of thoracolumbar intervertebral disk extrusion in chondrodystrophic dogs after surgical decompression with or without prophylactic fenestration: 265 cases (1995-1999). J Am Vet Med Assoc 224, 1808-1814.

Clarke KC, Sara L, McLafferty B, TempalskiJ, 1996. On epidemiology and geographic information systems: a review and discussion of future directions. Emerg Infect Dis 2, 85-92.

Cudia SP, Duval JM, 1997. Thoracolumbar intervertebral disk disease in large, nonchondrodystrophic dogs: a retrospective study. J Am Anim Hosp Assoc 33, 456-460.

da Costa RC, 2010. Cervical spondylomyelopathy (wobbler syndrome) in dogs. Vet Clin North Am Small Anim Pract 40, 881-913.

da Costa RC, Moore SA, 2010. Differential diagnosis of spinal diseases. Vet Clin North Am Small Anim Pract 40, 755-763.

Downes CJ, Gemmill TJ, Gibbons SE, McKee WM, 2009. Hemilaminectomy and vertebral stabilisation for the treatment of thoracolumbar disc protrusion in 28 dogs. J Small Anim Pract 50, 525-535.

Durr PA, Gatrell AC, 2004. GIS and spatial analysis in veterinary science. Wallingford, Oxfordshire, UK, CABI Publishing.

Evans HE, De Lahunta A, 2012. Miller's Anatomy of the Dog. Saunders.

Fitch RB, Kerwin SC, Hosgood G, 2000. Caudal cervical intervertebral disk disease in the small dog: role of distraction and stabilization in ventral slot decompression. J Am Anim Hosp Assoc 36, 68-74.

Fluckiger MA, Damur-Djuric N, Hassig M, Morgan JP, Steffen F, 2006. A lumbosacral transitional vertebra in the dog predisposes to cauda equina syndrome. Vet Radiol Ultrasound 47, 39-44.

Ganai S, Garb JL, Kanumuri P, Rao RS, Alexander AI, Wait RB, 2006. Mapping the rectum: spatial analysis of transanal endoscopic microsurgical outcomes using GIS technology. J Gastrointest Surg 10, 22-31.

Garb JL, Ganai S, Skinner R, Boyd CS, Wait RB, 2007. Using GIS for spatial analysis of rectal lesions in the human body. Int J Health Geogr 6, 11.

Goggin JE, Li AS, Franti CE, 1970. Canine intervertebral disk disease: characterization by age, sex, breed and anatomic site of involvement. Am J Vet Res 31, 1687-1692.

Hansen HJ, 1952. A pathologic-anatomical study on disc degen- eration in dog, with special reference to the so-called enchondrosis intervertebralis. Acta Orthop Scand Suppl 11, 1-117.

Israel SK, Levine JM, Kerwin SC, Levine GJ, Fosgate GT, 2009. The relative sensitivity of computed tomography and myelography for identification of thoracolumbar intervertebral disk herniations in dogs. Vet Radiol Ultrasound 50, 247-252.

Jeffery ND, Levine JM, Olby NJ, Stein VM, 2013. Intervertebral disk degeneration in dogs: consequences, diagnosis, treatment, and future directions. J Vet Intern Med 27, 1318-1333.

Juanes JA, Ruisoto P, Riesco JM, Prats A, 2012. Development of anatomical and radiological digital brain maps. Eur J Anat 16, 91-97.

Levine J, Levine G, Hettlich B, Kerwin S, Fosgate G, 2006. Association between various physical factors and acute thoracolumbar intervertebral disk extrusion or protrusion in Dachshunds. J Am Vet Med Assoc 229, 370-375.

Lim C, Kweon OK, Choi MC, Choi J, Yoon J, 2010. Computed tomographic characteristics of acute thoracolumbar intervertebral disc disease in dogs. J Vet Sci 11, 73-79.

Macias C, McKee WM, May C, Innes JF, 2002. Thoracolumbar disc disease in large dogs: a study of 99 cases. J Small Anim Pract 43, 439-446.

Newcomb B, Arble J, Rochat M, Pechman R, Payton M, 2012. Comparison of computed tomography and myelography to a reference standard of computed tomographic myelography for evaluation of dogs with intervertebral disc disease. Vet Surg 41, 207-214.

Olby NJ, Munana KR, Sharp NJ, Thrall DE, 2000. The computed tomographic appearance of acute thoracolumbar intervertebral disc herniations in dogs. Vet Radiol Ultrasound 41, 396-402.

Priester W, 1976. Canine intervertebral disc disease- occurrence by age, breed and sex among 8117 cases. Theriogenology 6, 293-301.

Reif JS, Cohen D, 1970. Canine pulmonary disease. II. Retrospective radiographic analysis of pulmonary disease in rural and urban dogs. Arch Environ Health 20, 684-689.

Rinaldi L, Musella V, Biggeri A, Cringoli G, 2006. New insights into the application of geographical information systems and remote sensing in veterinary parasitology. Geospat Health 1 , 33-47.

Schweikart J, La Torre F, Mannocci A, 2012. The geographical information system. Ital J Public Health 5, 241-244. 